\title{
ALOE VERA: AN ASSURED WEIGHT LOSS DIET - AN APPROACH TOWARD IMPROVING THE JUICE PALATABILITY AND IN SILICO ANALYSIS
}

\author{
DISALVA X ${ }^{1}$, SHARANYA M ${ }^{2 *}$, MAHENDRAN RADHA ${ }^{2}$ \\ ${ }^{1}$ Department of Hotel and Catering Management, Vels Institute of Science, Technology and Advanced Studies, Chennai, Tamil Nadu, India. \\ ${ }^{2}$ Department of Bioinformatics, Vels Institute of Science, Technology and Advanced Studies, Chennai, Tamil Nadu, India. \\ Email: sharanya.bioinfo@gmail.com
}

Received: 03 February 2019, Revised and Accepted: 16 April 2019

ABSTRACT

Objective: Obesity is an epidemic disease act as causative for global death. The principal aim of this study is to create an obesity treatment beverage that is palatable and readily acceptable to the public. Aloe vera juice is one such drink known to assist in reducing obesity. This juice is sold at several places in Chennai and more easily available for morning walkers along the Marina beach. Although known for its benefits in promoting a slim and fit physique, its taste is less palatable. The objective of this study is to develop a concoction that will make the $A$. vera juice tasty without compromising its nutritive value.

Materials and Methods: The taste is achieved by the addition of various fruit juices such as orange, lime, sweet lime, muskmelon, and pineapple with honey and stevia for sweetening. The weight loss ability of the prepared drinks is evaluated using pancreatic lipase inhibitory and the presence of phytochemicals. To the credit, the present study also determines the efficiency of $A$. vera compounds for its antiobesity property through in silico techniques. The significant interaction exhibited by the compounds with the antiobesity target inositol hexakisphosphate kinase 1 (IP6K1) was discussed.

Results: The recipe B containing orange juice: $A$. vera juice: stevia in the ratio 3:3:1 had good taste and the significant lipase activity. The phytochemicals present in the $A$. vera are tannins, flavonoids, alkaloids, steroids, and polyphenols, and these phytochemicals are observed having significant interaction with protein IP6K1. Aloin A and aloe emodin had significant Glide score and interactions with active site residues.

Conclusion: Natural herbal products for weight reduction may be effective in the treatment of obesity and associated disorders. The potential lipase inhibition activity of juice may be due to the presence of various phytochemicals such as flavonoids, polyphenol etc. in the Aloe vera.

Keywords: Obesity, Aloe vera, Weight loss, Aloe vera juice, In silico analysis, Docking studies, Inositol hexakisphosphate kinase 1.

(C) 2019 The Authors. Published by Innovare Academic Sciences Pvt Ltd. This is an open access article under the CC BY license (http://creativecommons. org/licenses/by/4. 0/) DOI: http://dx.doi.org/10.22159/ajpcr.2019.v12i6.32380

\section{INTRODUCTION}

In the present era, obesity is one among the causes for global death and other diseases. It is an epidemic disease with increased comorbidity for Type 2 diabetes, coronary heart disease, stroke, fatty liver, neurodegeneration, cerebrovascular disease, congestive heart failure, hypertension, lipoprotein abnormalities, and several diseases [1]. Obesity is an abnormal or excessive fat accumulation to the body and could be explained as a body mass index, $\mathrm{kg} / \mathrm{m}^{2}$. More recently, Guthold et al. [2] published that $28 \%$ or 1.4 billion people are physically inactive which increases the risk for obesity and the development of non-communicable diseases. Despite physical inactivity, excess intake of food, especially processed junk foods, endocrine disorders, genes, medications, and mental disorders also have its role in the cause of obesity $[3,4]$.

Aloe vera, a common medicinal, readily available, cactus-like plant has several medicinal applications in treating many ailments. Christaki and Florou-Paneri [5] reviewed the worth of $A$. vera under the categories cosmetic, medicinal, food, and nutrition. This plant being used since Rigvedic times in India, being reported for its medicinal property such as treating wounds and burns, protection for skin from X-rays, lung cancer, intestinal problems, reduces the blood sugar level in diabetic patients and low-density lipoprotein, increase the highdensity lipoprotein, improves the immune system as well as to fight the acquired immune deficiency syndrome (AIDS), and allergies [6,7]. A. vera gained its industrial importance and the value for their products roughly calculated around $\$ 125$ million and the recent thrust in utilizing herbal medicines have enlightened its significance in the industrial development [6]. A report was found that Americans spend 40 billion dollars on Aloe products as functional foods, drinks, and nutritional supplements [6]. Aloe juices are widely used as a health drink, soft drink, laxative drink, sherbet and along with several components such as lemon juice, electrolyte, soluble fiber, Vitamin B, amino acids and acetaminophen, other vegetables, yogurts, and cucumber [8]. Due to its multi-application, the Chinese called the plant as Elixir of youth. The intake of Aloe preparations as a whole leaf extract and as an inner fillet gel enhanced the uptake of water/fat-soluble vitamins in the body and it is the only supplement known for this ability [9]. The applications of Aloe in health are enormous and scientific records on its antiacid, antipeptic, gastroprotective, and antiulcer [10].

The emergence of bioinformatics has led the drug discovery and development process much easier, also cost effective and the existing high throughput sequencing techniques added its value. In addition, the juice prepared as a daily dietary ingredient, the present study focuses to study the potentials of $A$. vera compounds in interacting the antiobesity target inositol hexakisphosphate kinase 1 (IP6K1). The target chosen has significant functionality in regulating cell metabolism and survival [11]. The recent studies have found that deletion of adipocytespecific IP6K1 modulates AMP-activated protein kinase -mediated adipocyte energy metabolism thereby regulates the fat accumulation in the body [12]. Secondary metabolites of plants have gained momentum in the process of drug discovery. Recently, arteether, galantamine, nitisinone, and tiotropium have been introduced in the US market [13]. Even more, the plant natural compounds were scientifically evaluated its efficiency against several dreadful diseases such as cancer, HIV/ AIDS, Alzheimer's, and malaria [14]. 


\section{MATERIALS AND METHODS}

\section{Beverage preparation}

The beverage preparation consists of three steps which include juice processing of selected fruits for improving taste, $A$. vera juice processing and beverage preparation. The three citrus fruits juices of mosambi, orange, and lemon as well as the pineapple and muskmelon were chosen and added with natural sweeteners in the form of powder (stevia and honey). The A. vera leaves were bought from Pallavaram Market, Chennai. The juices of each fruit were prepared in the following methods. The skins of mosambi was removed and roughly blended to extract the juice and stored immediately since citrus fruits have a tendency to turn to bitter taste. In the case of orange and lemon, squeezing techniques were used to obtain the extract and mixed with $3 / 4^{\text {th }}$ of water. In pineapple and muskmelon, the skin was removed, and the pulp was diced into pieces to prepare as juice. The prepared juices were kept aside and/or stored in the refrigerator until the $A$. vera leaves were extracted. $A$. vera leaves were peeled, diced, and washed several times to remove the stickiness and pulp was extracted by the blending method and processed into juice. Furthermore, it was filtered through a strainer and stored in clean glass jar. As a final step, the beverage was prepared by mixing together the $30 \mathrm{ml}$ of each fruit juices with $30 \mathrm{ml}$ of $A$. vera juice separately. The mixture was blended nicely using cocktail shaker with the addition of sweeteners. The recipe formulation was tabulated (Table 1).

\section{Determination of phytochemicals and nutraceuticals}

Phytochemical analysis

The phytochemical analysis was carried out for the food samples prepared for the presence of tannins, flavonoids, steroids, alkaloids, and polyphenols [15-17]. The samples were extracted with hydroalcoholic solvents $(70 \%)(70 \mathrm{ml}$ ethanol and $30 \mathrm{ml}$ of water) for $24 \mathrm{~h}$, and the filtrates were analyzed for phytochemicals.

\section{Test for tannins}

About $1 \mathrm{ml}$ of the sample was boiled in $20 \mathrm{ml}$ of water in a test tube and then filtered. A few drops of $0.1 \%$ ferric chloride was added and observed for brownish green or a blue-black coloration.

\section{Test for flavonoids}

About $5 \mathrm{ml}$ of dilute ammonia solution were added to a portion of the aqueous filtrate of each plant extract followed by addition of concentrated $\mathrm{H}_{2} \mathrm{SO}_{4}$. A yellow coloration observed in each extract indicated the presence of flavonoids. The yellow coloration disappeared on standing.

Table 1: Composition of concoction

\begin{tabular}{lllll}
\hline S. No. & $\begin{array}{l}\text { Recipe } \\
\text { formulation }\end{array}$ & $\begin{array}{l}\text { Quantity } \\
\text { of fruits } \\
\text { juice (ml) }\end{array}$ & $\begin{array}{l}\text { Quantity } \\
\text { of } \text { A. vera } \\
\text { juice (ml) }\end{array}$ & $\begin{array}{l}\text { Quantity of } \\
\text { stevia (g) }\end{array}$ \\
\hline 1 & A & Lemon -30 & 30 & 10 \\
2 & B & Orange -30 & 30 & 10 \\
3 & C & Sweet Lime -30 & 30 & 10 \\
4 & D & Pineapple -30 & 30 & 10 \\
5 & E & Muskmelon -30 & 30 & 10 \\
\hline \multicolumn{2}{l}{ A. vera: Aloe vera } & &
\end{tabular}

Table 2: Phytochemicals analysis of different juices

\begin{tabular}{|c|c|c|c|c|c|c|}
\hline \multirow[t]{2}{*}{ S. No. } & \multirow[t]{2}{*}{ Juice varieties } & \multicolumn{5}{|c|}{ Phytochemicals } \\
\hline & & Tannin & Flavonoids & Steroids & Alkaloids & Polyphenols \\
\hline 1 & Lemon with $A$. vera & + & ++ & + & + & ++ \\
\hline 2 & Orange with $A$. vera & + & ++ & + & + & ++ \\
\hline 3 & Sweet lime with $A$. vera & + & ++ & ++ & + & ++ \\
\hline 4 & Pine apple with $A$. vera & + & ++ & + & + & ++ \\
\hline 5 & Muskmelon with $A$. vera & + & ++ & + & + & ++ \\
\hline
\end{tabular}


which contains 441 amino acids and the mass of 50,236 Da. Further, the retrieved sequence was subjected for alignment using the proteinprotein basic local alignment search tool (BLAST) against the protein structure database (Protein Data Bank [PDB]), to identify the structure of similar proteins for protein modeling. The structure prediction was carried out using the online Tool I-Tasser, and was an automated structure prediction tools from the structure-based function annotation (https://zhanglab.ccmb.med. umich.edu/I-TASSER/). The quality of the modeled structure was studied from the Ramachandran Plot obtained using the tool, RamPage (http://mordred.bioc.cam.ac.uk/ rapper/ rampage.php). Before the energy of the structure was minimized using Swiss PDB viewer. The active site pocket for the modeled protein structure was predicted using SCFbio (http://www.scfbio-iitd.res. in/dock/ActiveSite.jsp). Plant compounds emodin, anthracene, aloeemodin, chrysophanic acid, anthranol, aloin B, aloetic acid, aloin, aloin A, and the Food and Drug Administration approved drugs for obesity, orlistat, and phentermine in three dimensional. sdf file format was retrieved from the PubChem database (https://pubchem.ncbi.nlm. nih.gov/). Further, the docking studies were carried out using Glide module of Schrodinger software to analyze the docking score, and the interactions with specific residues along with the length of bond formation were visualized in PyMol software.

\section{RESULTS AND DISCUSSION}

Functional foods are defined as foods that contain bio-active ingredients thought to enhance health and fitness. The active ingredients are phytochemicals, such as lycopene in tomatoes, allicin in garlic, or isoflavones in soybeans. These phytochemicals, also called "nutraceuticals," may be extracted and consumed as supplements, or may have therapeutic value when consumed in whole food. Majority of foods, such as whole grains, beans, fruits, vegetables, and herbs contain phytochemicals of nutraceutical importance. These phytochemicals, either alone and/or in combination, have tremendous therapeutic potential in curing various ailments including cancer, diabetic, obesity, arthritis, ulcer, cardiovascular diseases, and hypertension [20]. Natural products provide a vast pool of pancreatic lipase inhibitors [21]. A wide variety of plant products such as saponins, polyphenols, flavonoids, and caffeine possess lipase inhibitors. Natural products can play a safe and effective role with obesity especially those containing fibers, polyphenols, sterols, and alkaloids [22]. In the present study, tannin, flavonoids, steroids, alkaloid, and polyphenol were present in the tested sample (Table 2). The presence of these compounds indicates the positive effect on health.

\section{Determination of weight loss}

In the present era, human population faces obesity as the major problem. However, the number of agents and their products is utilized for weight loss; perhaps the side effects are the issues to be concerned. Hence, consistent and safe herbal product for weight reduction is the urgent need in developing countries. The developed juice varieties were observed for lipase inhibition and the results are discussed (Table 3).

Lipase inhibitors may be effectiveness in reducing dietary fat intake by reducing both the consumption and absorption of fat [23]. Dietary fat is absorbed by the intestine when it has been subjected to the action of pancreatic lipases. Pancreatic lipase is a key enzyme in dietary triacylglycerol absorption, hydrolyzing triacylglycerols to monoacylglycerols, and fatty acids. Digestion and absorption of dietary lipids by pancreatic lipase, a major source of excess calorie intake, can be targeted for the development of weight loss agents. Pancreatic lipase inhibition is one of the most widely studied mechanisms used to determine the potential efficacy of natural products as antiobesity agents. Hence, in the present study, lipase was isolated from the chicken pancreas and determined the inhibitory activity of pancreatic lipase when incubated with different concentrations from 50,100, 150, and $150 \mathrm{ml}$ of Lemon with $A$. vera, orange with $A$. vera, sweet lime on with $A$. vera, pineapple with $A$. vera, and muskmelon with $A$. vera juice. Many fruits and herbal teas have been extensively studied for the pancreatic lipase inhibition due to the presence of polyphenols [24,25].

With the increase in the concentration of extracts, the higher inhibition of the enzyme was observed. The order of lipase inhibition activity was Lemon with $A$. vera>Pineapple with $A$. vera>Muskmelon with $A$. vera $>$ Orange with $A$. vera $>$ Sweet lime on with $A$. vera. Comparatively lemon with $A$. vera juice showed maximum inhibition against enzyme lipase whereas the lowest inhibition was sweet lime on with $A$. vera juice. Thus, an inhibitor of digestive lipase that helps to limit intestinal fat absorption could be proved as useful medication for the treatment of hyperlipidemia and holds great promise as a weight loss agent. Among the various juice, lemon with $A$. vera juice possesses potential lipase inhibitors than other juice.

\section{In silico analysis}

\section{Protein structure modeling}

The protein IP6K1 from $H$. sapiens contains 441 amino acids, and the sequence was subjected for BLAST analysis. The hits obtained have only $32 \%$ of similarity against the PDB database; however, for obtaining a qualified structure, the template should be selected on the basis of selection rule with the highest sequence similarity [26]. Since in the present analysis, the percentage obtained was $32 \%$, the multiple template-based structure prediction was performed; multiple template selection would increase the model accuracy [27]. I-Tasser generated five models, each with a C-score of $-2.48,-2.72$, $-2.90,-3.95$, and -2.74 , respectively, whereas the estimated TMScore and RMSD were $0.43 \pm 0.14$ and $13.0 \pm 4.2 \AA$, respectively. The modeled structure was energy minimized using Swiss PDB viewer of $-14389.468 \mathrm{KJ} / \mathrm{Mol}$ and the structure is shown in Fig. 1 . The active sites were determined as THR 101, ASP 106, THR 107, THR 108, GLU 109, ARG 110, GLU 111, GLN 112, PRO 113, ARG 114, ARG 115, LYS 116, SER 118, ARG 119, ARG 124, SER 125, GLY 126, SER 127, GLY 18, SER 129, ASP 130, GLU133, GLU134, SER 137, LEU138,

Table 3: Lipase activity of different juices

\begin{tabular}{lllll}
\hline Name of the juice & \multicolumn{4}{l}{ Concentration (ml) } \\
\cline { 2 - 5 } & $\mathbf{0 . 5 0}$ & $\mathbf{1 . 0 0}$ & $\mathbf{1 . 5 0}$ & $\mathbf{2 . 0 0}$ \\
\hline Lemon with A. vera & 8.50 & 7.80 & 7.20 & 6.32 \\
Orange with A. vera & 9.50 & 8.60 & 8.10 & 7.80 \\
Sweet lime with A. vera & 10.20 & 9.70 & 8.50 & 8.10 \\
Pineapple with A. vera & 9.20 & 8.50 & 7.80 & 7.10 \\
Muskmelon with $A$. vera & 9.80 & 8.70 & 8.20 & 7.40 \\
\hline
\end{tabular}

A. vera: Aloe vera

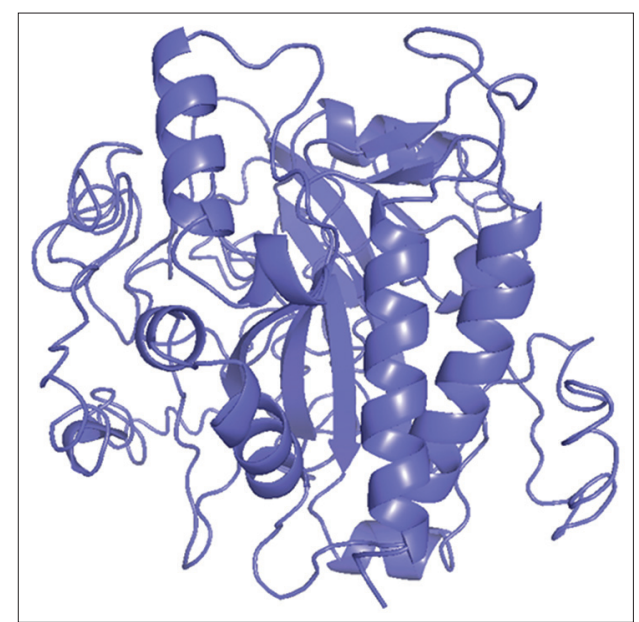

Fig. 1: Structure of modeled protein-inositol hexakisphosphate kinase 1 
Table 4: Absorption, distribution, metabolism, and excretion properties of $A$. vera compounds

\begin{tabular}{|c|c|c|c|c|c|c|c|}
\hline \multirow[t]{2}{*}{ Compound name } & $\begin{array}{l}\text { Molecular } \\
\text { weight }\end{array}$ & $\begin{array}{l}\text { Donor } \\
\text { HB }\end{array}$ & $\begin{array}{l}\text { Acceptor } \\
\text { HB }\end{array}$ & $\begin{array}{l}\text { QPlogPo/w Predicted } \\
\text { octanol/water } \\
\text { partition coefficient }\end{array}$ & SASA & $\begin{array}{l}\text { QPlog BB Predicted } \\
\text { blood/blood } \\
\text { partition coefficient }\end{array}$ & $\begin{array}{l}\text { Human Oral } \\
\text { Absorption }\end{array}$ \\
\hline & $130.0-725.0$ & $0.0-6.0$ & $2.0-20.0$ & $-2.0-6.5$ & $300.0-1000.0$ & $-3.0-1.2$ & $\begin{array}{l}\text { 1, } 2 \text { or } 3 \text { for low, } \\
\text { medium or high }\end{array}$ \\
\hline Orlistat (3034010) & 495.741 & 0.25 & 7.75 & 21.148 & 961.847 & -2.678 & 1 \\
\hline Emodin (3220) & 270.241 & 1 & 4.25 & 12.607 & 479.225 & -1.541 & 3 \\
\hline Phentermine (4771) & 149.235 & 2 & 1 & 8.782 & 383.538 & 0.487 & 3 \\
\hline Anthracene (8418) & 178.233 & 0 & 0 & 7.45 & 404.551 & 0.192 & 1 \\
\hline Aloe-emodin (10207) & 270.241 & 1 & 5.2 & 12.997 & 478.805 & -1.594 & 3 \\
\hline Chrysophanic acid (10208) & 254.242 & 0 & 3.5 & 10.583 & 466.991 & -0.987 & 3 \\
\hline Anthranol (10731) & 194.232 & 1 & 0.75 & 9.357 & 411.593 & 0.193 & 3 \\
\hline Aloin B (14989) & 418.399 & 5 & 11.7 & 26.431 & 626.291 & -2.823 & 1 \\
\hline Aloetic acid (5464178) & 450.231 & 1 & 9.2 & 18.705 & 597.175 & -4.481 & 1 \\
\hline Aloin A (12305761) & 418.399 & 5 & 11.7 & 26.634 & 641.8 & -3.064 & 1 \\
\hline
\end{tabular}

HB: Hydrogen bond, QPlogPo/w: Octanol/water coefficient, SASA: Solvent accessibility of surface area, QPlogBB: Blood-brain barrier, A. vera: Aloe vera

Table 5: Docking studies for IP6K1 with $A$. vera compounds

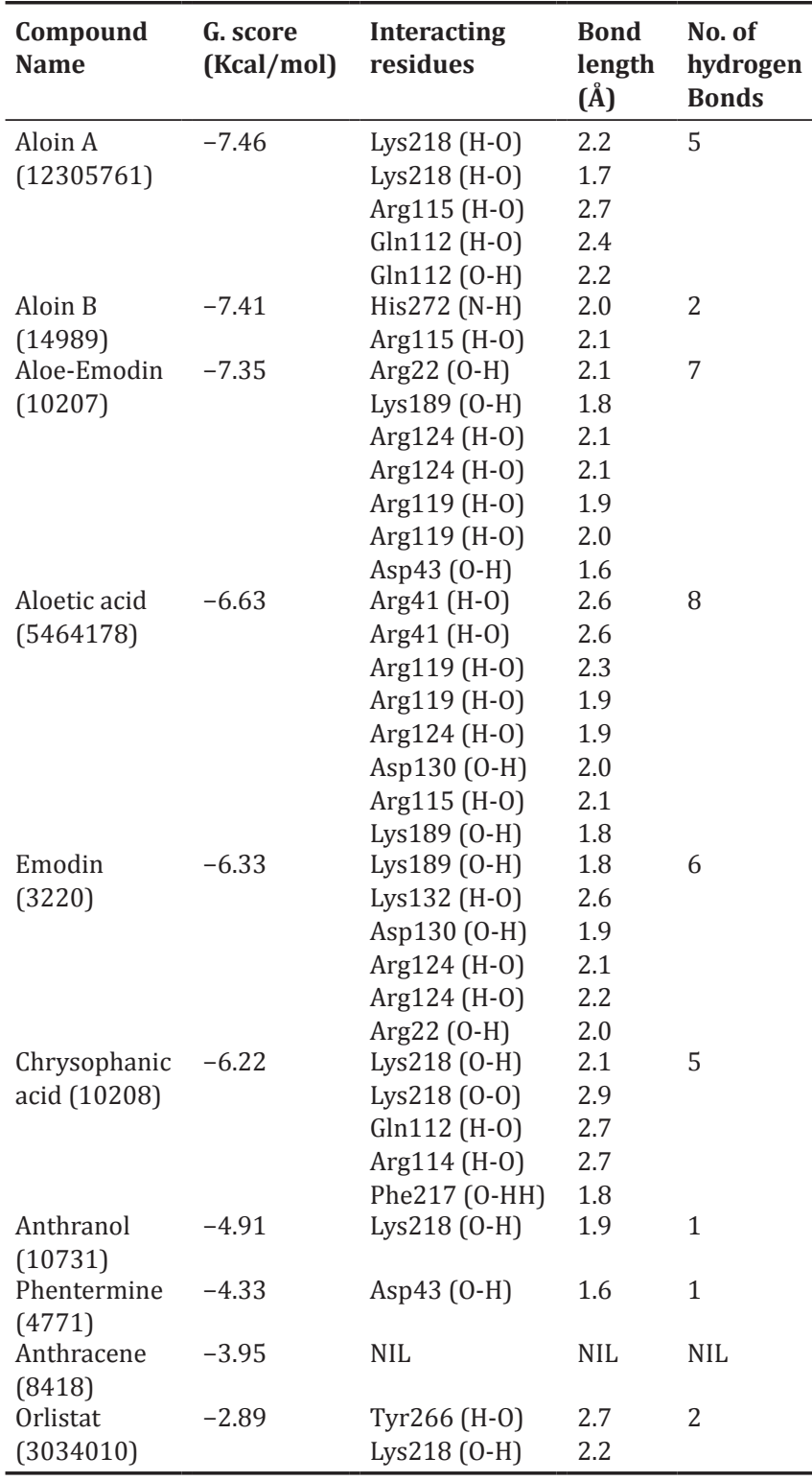

IP6K1: Inositol hexakisphosphate kinase 1
VAL214, PHE217, LYS218, TYR219, PR0220, GLN264, TYR266, GLN267, ASP269, GLY271, TYR273, GLY341, LYS342, GLU343, ARG345, GLU347, and SER348.

Absorption, distribution, metabolism, and excretion (ADME) properties

The absorption, distribution, metabolism, and excretion properties were determined for the $A$. vera compounds and drug molecule orlistat (Table 4). All the compounds analyzed had higher log $\mathrm{p}$ value; however, violation of single Lipinski rule of five is accepted. The molecules phentermine, antracene, anthranol had a less molecular weight $<200$, emodin, aloe-emodin, and chrysophanic acid had in the range of 200-300, whereas orlistat, aloin B, aloetic acid, and aloin A had $>400$. Donor and acceptor hydrogen bond are most important since those are involved in the formation of significant interaction between the compound and the protein. The compound anthracene had no ability to donate as well as to accept the hydrogen bonds. The surface area solvent accessible is important criteria which reveal the polar interaction and the solubility of the compounds in the water environment. The compounds studied in the present research indicated significant solvent accessibility of surface area value. The table also shows the blood/blood partition coefficient for the compounds which ranges between the -3.0 and 1.2 and the human oral absorption was determined to predict the ability of the compounds for oral intake. The drug orlistat had a low level of oral absorption whereas the compounds emodin, phentermine, aloe-emodin, chrysophanic acid, and anthranol had significantly high for oral absorption.

\section{Docking analysis}

The docking studies for the compounds and drug orlistat with the protein IP6K1 1 were determined using the software Glide, a Schrodinger suite. The Glide score (G. Score), interacting residues, bond length, and number of hydrogen bonds were tabulated (Table 5). The plant compounds had significant G. score value that the drug orlistat where the G. score was observed to be $-2.89 \mathrm{Kcal} / \mathrm{mol}$. Among the plant compounds, aloin A had significant G. score of $-7.46 \mathrm{Kcal} / \mathrm{mol}$ followed by aloin $B$ and aloe emodin of -7.41 and $-7.35 \mathrm{Kcal} / \mathrm{mol}$, respectively. The respective G. score of aloetic acid, emodin, and chrysophanic acid is $-6.63,-6.33$, and $-6.22 \mathrm{Kcal} / \mathrm{mol}$. The compounds anthranol and phentermine had $\mathrm{G}$. score in the range of -4 and anthracene had $-3.95 \mathrm{Kcal} / \mathrm{mol}$. The interactions were higher to lower in the order of aloetic acid>aloe emodin>emodin>aloin A, chrysophanic acid, orlistat>aloin B>anthranol, phentermine.

The interactions with active sites include GLN 112, ARG 115, ARG 119, ARG 124, ASP 130, PHE 217, LYS 218, and TYR 266. Perhaps, apart 
Table 6: Snapshots of docking complex of compounds with protein IP6K1

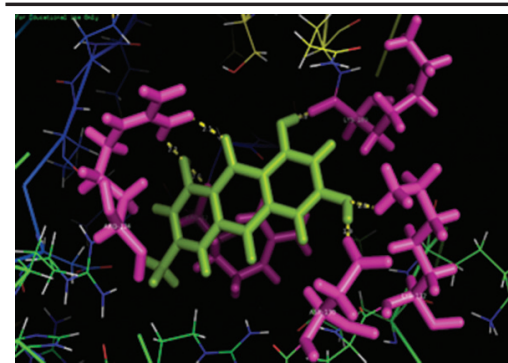

Emodin versus IP6K1

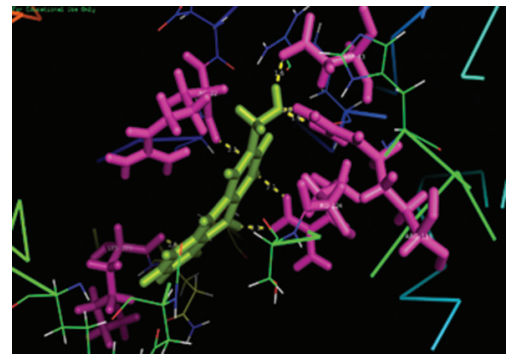

Aloe-Emodin versus IP6K1

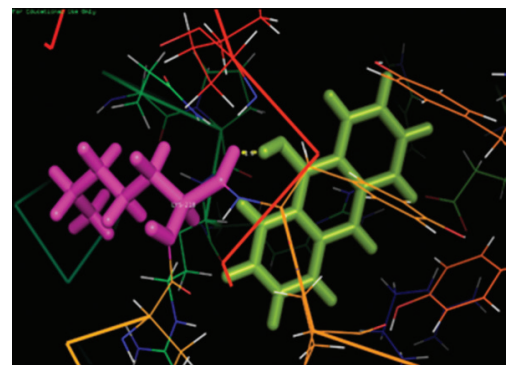

Anthranol versus IP6K1

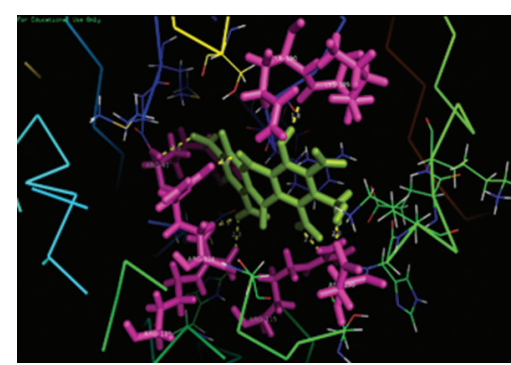

Aloetic acid versus IP6K1

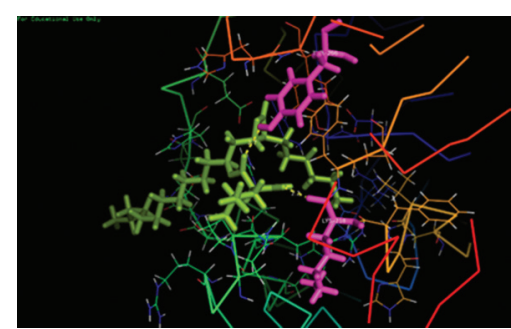

Orlistat versus IP6K1

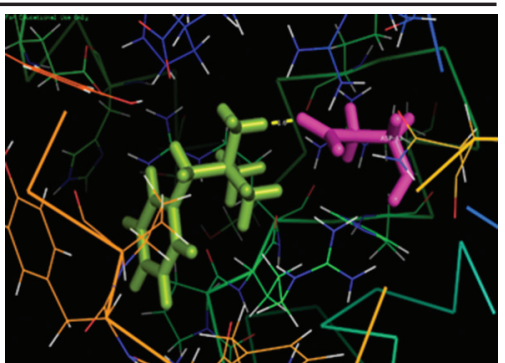

Phentermine versus IP6K1

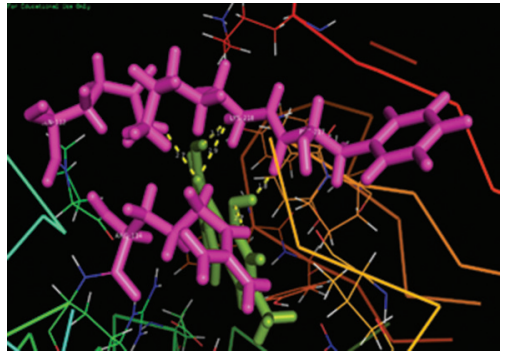

Chrysophanic acid versus IP6K1

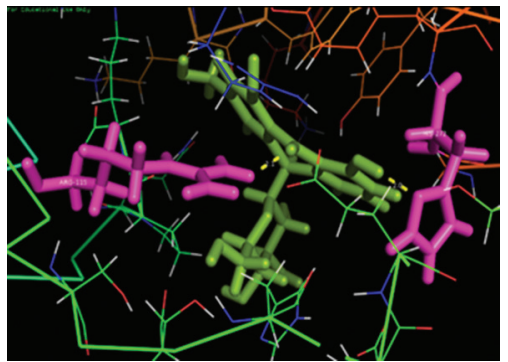

Aloin B versus IP6K1

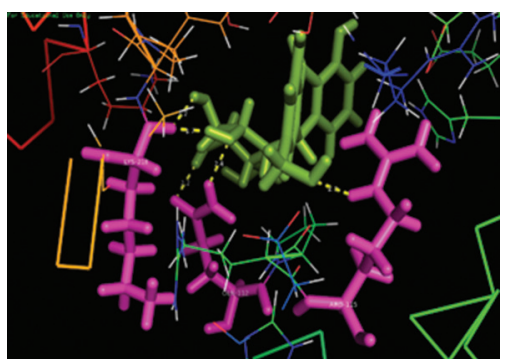

Aloin A versus IP6K1

IP6K1: Inositol hexakisphosphate kinase 1

from active sites, the following are the residues had interactions with the plant compounds and orlistat, ARG22, ARG 41, ASP 43, ARG 114, LYS 132, and LYS 189. The interactions of each compound with the protein IP6K1 are shown in Table 6. The compound anthracene had no interactions as it has no hydrogen donor and hydrogen acceptor property as predicted in the ADME analysis.
The in silico studies indicated the efficiency of $A$. vera compounds in interacting with the target protein IP6K1 and the ADME properties also indicated its human oral absorption property. The plant is reported in cleansing the digestive system and encourages in relaxing constipation as well as increases the energy levels to maintain a healthy body weight [28] 


\section{CONCLUSION}

Obesity is characterized as abnormal or excessive fat deposition in adipose tissue and other internal organs such as liver, heart, and skeletal muscle. It is a chronic disorder of carbohydrate and fat metabolism and poses a risk to the health and well-being of humans. Consistent and safe herbal product for weight reduction is a need in developing countries. Natural herbal products for weight reduction may be effective in the treatment of obesity and associated disorders. The potential lipase inhibition activity of juice may be due to the presence of various phytochemicals such as flavonoids, polyphenol etc. in the Aloe vera.

\section{AUTHOR'S CONTRIBUTIONS}

The author declares that this work was done by the author named in this article.

\section{CONFLICTS OF INTEREST}

No conflicts of interest are associated with this work.

\section{REFERENCES}

1. Berthoud HR, Klein S. Advances in obesity: Causes, consequences, and therapy. Gastroenterology 2017;152:1635-7.

2. Guthold R, Stevens GA, Riley LM, Bull FC. Worldwide trends in insufficient physical activity from 2001 to 2016: A pooled analysis of 358 population-based surveys with 1.9 million participants. Lancet Glob Health 2018;6:e1077-86.

3. Karam JG, McFarlane SI. Secondary causes of obesity. Therapy 2007;4:641-50.

4. Bollapragada MK, Shantaram M, Kumar RS. Obesity: Development, epidemiology, factors affecting, quantity, health hazards, management and natural treatment a review. Int J Pharm Pharm Sci 2017;9:12-26.

5. Christaki EV, Florou-Paneri PC. Aloe vera: A plant for many uses. J Food Agric Environ 2010;8:245-9.

6. Ahlawat KS, Khatkar BS. Processing, food applications and safety of Aloe vera products: A review. J Food Sci Technol 2011;48:525-33.

7. Subhashis P, Dutta S, Chaudhuri TK, Bhattacharjee SB. Antiinflammatory and protective properties of Aloe vera leaf leaf crude gel in carrageenan induced acute inflammatory rat models. Int J Pharm Pharm Sci 2014;6:368-71.

8. Singh A, Singh AK. Optimization of processing variables for the preparation of herbal bread using Aloe vera gel. J Food Sci Technol 2009; 46:335-8.

9. Vinson JA, Al Kharrat H, Andreoli L. Effect of Aloe vera preparations on the human bioavailability of Vitamins $\mathrm{C}$ and E. Phytomedicine 2005; 12:760-5.

10. Borrelli F, Izzo AA. The plant kingdom as a source of anti-ulcer remedies. Phytother Res 2000;14:581-91.

11. Chakraborty A, Koldobskiy MA, Bello NT, Maxwell M, Potter JJ,
Juluri KR, et al. Inositol pyrophosphates inhibit akt signaling, thereby regulating insulin sensitivity and weight gain. Cell 2010;143:897-910.

12. Zhu Q, Ghoshal S, Rodrigues A, Gao S, Asterian A, Kamenecka TM, et al. Adipocyte-specific deletion of ip6k1 reduces diet-induced obesity by enhancing AMPK-mediated thermogenesis. J Clin Invest 2016;126:4273-88

13. Balunas MJ, Kinghorn AD. Drug discovery from medicinal plants. Life Sci 2005;78:431-41.

14. Liu J, Pei M, Zheng C, Li Y, Wang Y, Lu A, et al. A systemspharmacology analysis of herbal medicines used in health improvement treatment: Predicting potential new drugs and targets. Evid Based Complement Alternat Med 2013;2013:938764.

15. Sofowora A. Medicinal Plants and Traditional Medicinal in Africa. $2^{\text {nd }}$ ed. Sunshine House, Ibadan, Nigeria: Spectrum Books Ltd.; 1993.

16. Trease GE, Evans WC. Pharmacognosy. $13^{\text {th }}$ ed. London: ELBS/ Bailliere Tindall; 1989

17. Harborne JB. Phytochemical methods. London chapman and Hall Ltd., 1984.

18. Choi SJ, Hwang JM, Kim SI. A colorimetric microplate assay method for high throughput analysis of lipase activity. J Biochem Mol Biol 2003;36:417-20.

19. Kekuda TR, Raghavendra HL, Mallikarjun N, Venugopal TM, Kumar HS. Elemental composition, anticarcinogenic, pancreatic lipase inhibitory and cytotoxic activity of Artocarpus lakoocha Roxb pericarp. Int J Drug Dev Res 2012;4:330-6.

20. Prakash D, Gupta C, Sharma G. Importance of phytochemicals in nutraceuticals. J Chin Med Res Dev 2012;1:70-8.

21. Birari RB, Bhutani KK. Pancreatic lipase inhibitors from natural sources: Unexplored potential. Drug Discov Today 2007;12:879-89.

22. Shimoda H, Seki E, Aitani M. Inhibitory effect of green coffee bean extract on fat accumulation and body weight gain in mice. BMC Complement Altern Med 2006;6:9-13.

23. Ellrichmann M, Kapelle M, Ritter PR, Holst JJ, Herzig KH, Schmidt WE, et al. Orlistat inhibition of intestinal lipase acutely increases appetite and attenuates postprandial glucagon-like peptide-1(7-36)-amide-1, cholecystokinin, and peptide YY concentrations. J Clin Endocrinol Metab 2008;93:3995-8.

24. Nakai M, Fukui Y, Asami S, Toyoda-Ono Y, Iwashita T, Shibata H, et al. Inhibitory effects of oolong tea polyphenols on pancreatic lipase in vitro. J Agric Food Chem 2005;53:4593-8.

25. Li F, Li W, Fu H, Zhang Q, Koike K. Pancreatic lipase-inhibiting triterpenoid saponins from fruits of Acanthopanax senticosus. Chem Pharm Bull (Tokyo) 2007;55:1087-9.

26. Fiser A. Template-based protein structure modeling. Methods Mol Biol 2010;673:73-94.

27. Fernandez-Fuentes N, Madrid-Aliste CJ, Rai BK, Fajardo JE, Fiser A. M4T: A comparative protein structure modeling server. Nucleic Acids Res 2007:35:W363-8.

28. Rajeswari R, Umadevi M, Rahale S, Pushpa R, Selvavenkadesh S, Kumar KP, et al. Aloe vera: The miracle its medicinal and traditional uses in India. J Pharmacogn Phytochem 2012;1:118-24. 